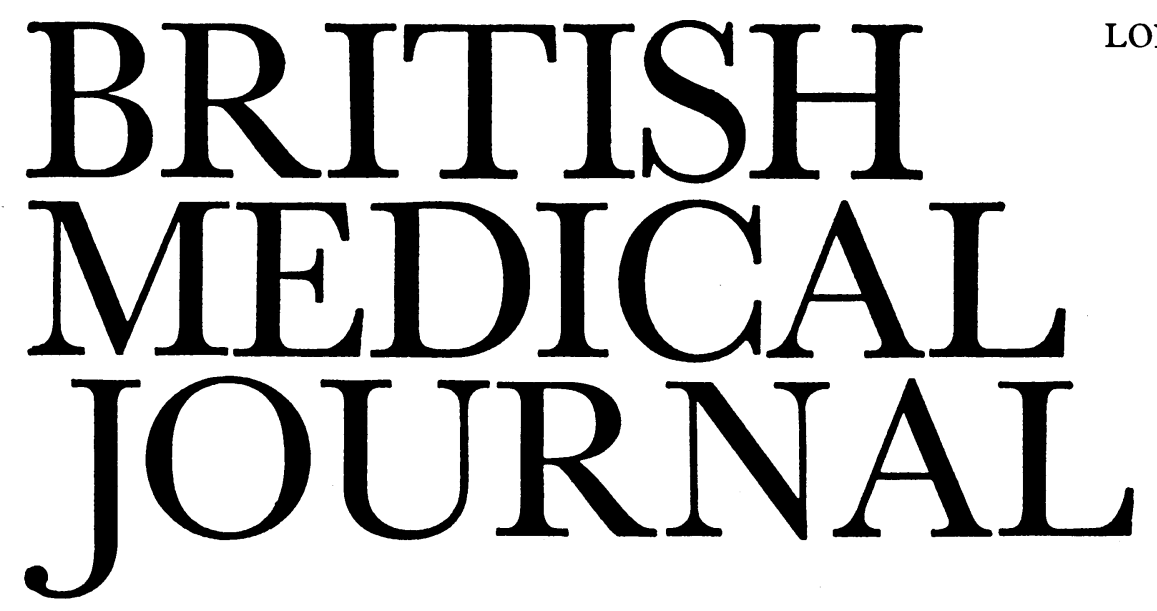

\title{
Liverpool: where does the buck stop?
}

The committee of inquiry set up to examine the affairs of the Liverpool Area Health Authority has come up with one of the most devastating, and depressing, reports yet published about the reorganised Health Service. ${ }^{1}$ For though the report deals only with the situation in one AHA with a quite exceptional concentration of problems, it also raises some wider doubts about the quality of management in the NHS and the competence of decision-making in the Department of Health and Social Security.

The circumstances that prompted the appointment of the committee of inquiry, under the chairmanship of Professor Roger Dyson, were remarkable in themselves. By the summer of 1977, in the words of the report, the AHA was "in danger of being no longer able to guarantee the provision of its health services." It had antagonised many of its staff and aroused the opposition of the public. The announcement of "a dramatic programme of financial limitations involving the closure of many wards and a reduction in manning levels" in one of its two districts had set off an explosion of protest and brought together a coalition of trade unions and community health councils in opposition. The committee of inquiry was thereupon set up by Mersey Regional Health Authority after the intervention of Mr Roland Moyle, Minister of State, DHSS.

The difficulties of Liverpool AHA were partly inherited, partly self-inflicted, and partly the consequence of Government policy. Inner Liverpool, like inner London, has its own special characteristics. The AHA had inherited from the nineteenth century an over-generous provision of beds, ${ }^{2}$ exacerbated by the outward movement of the city's population. Moreover, the AHA's acknowledged surplus of beds was further compounded by the building of a new teaching hospital. This, after a long and notorious history of delays and escalating costs, ${ }^{3}$ is now almost ready for commissioning. The DHSS's interest in the affairs of Liverpool doubtless reflects its concern that the opening of this $£ 60$ million hospital should not be further held up by local bickerings. So the AHA was faced with the necessity not only of cutting the number of beds in line with national norms-which would have been painful enough-but also of closing existing facilities to free the resources needed to run the new teaching hospital.

The committee of inquiry-the findings of which are summed up by Professor Dyson on p 383-endorses the AHA's immediate programme of closures, with a few minor reservations, as both reasonable and essential in the circumstances. Some opposition was inevitable, given the scale of the closures required: the conservative coalition of trade unions and $\mathrm{CHCs}$, defending the status quo in terms of jobs and the distribution of facilities, is by no means unique to Liverpool. But the report also suggests that the violence of the opposition largely reflects the ineptitude of the AHA's handling of its relations with both staff and public. Many of its injuries were, in effect, selfinflicted.

The AHA's decision to amalgamate its two districts, the report emphasises, produced a crisis of morale among its staff and an exodus of managers. Nor did the time taken by the DHSS to agree to this proposal-18 months-improve matters. Militancy among staff, especially among members of NUPE, was reinforced by the AHA's failure to consult early and fully enough. The outcome was a state of "guerrilla warfare" in one part of the AHA. And while the AHA can scarcely be blamed for union militancy, it certainly can be blamed for its failure to introduce an effective industrial relations system - a failure that is amply documented in the report. Astonishingly, the committee points out, the authority "has never formally debated the general subject of industrial relations nor does it receive information on this subject on a regular basis." Moreover, in a period of mounting crisis the average attendance rate for AHA members was only 50\% - and less than $40 \%$ for local authority representatives. So much for Mrs Barbara Castle's argument that increasing the number of local authority representatives on AHAs would inject a greater element of "democracy" into the NHS.

The AHA, the report argues, also made life difficult for itself in other respects. Reducing the number of hospital beds would clearly be easier if community health care and social support could be improved; the need for improving these is particularly urgent in a city like Liverpool, with its high concentration of social stress, poverty, and unemployment. But Liverpool AHA appears to have given little priority to this policy and to have shown little interest in the opportunities presented by the extra money available under the Government's programme for joint funding with local authorities. This does not seem to have been entirely the fault of the AHA. The committee of inquiry's report suggests that the local authority was more than somewhat uncooperative. In any event, local authority representation on the AHA does not-to judge from the Liverpool experience-ensure the co-ordination of the health and other local social services; nor does the present system provide any opportunity for knocking reluctant heads together. 
Indeed, as the report recognises, the ability of any AHA to develop community or primary care is limited. As it rightly emphasises, this is largely a matter of national policy. And the DHSS has yet to devise any sort of policy for improving primary care in inner city areas, though it is not only Liverpool that has an above average number of singlehanded, aging GPs, often working in unsatisfactory conditions, who rely greatly on deputising services. One solution, the report suggests, might be to give special payments to inner city practices. Whether or not this is the best way of addressing the problem, the DHSS should certainly be seeking to strengthen primary care as part of the Government's new programme for investing extra resources in the decaying inner cities of Britain.

The responsibility of the DHSS does not end there, however. The crisis in Liverpool was precipitated-though not: caused-by introducing the RAWP formula for apportioning NHS resources. ${ }^{4}$ In particular, Liverpool was hard hit by the decision to withdraw the special funding for the revenue consequences of capital schemes; this is why financing the new teaching hospital has turned out to be such a nightmare. To make matters even worse, the report argues, Mersey RHA's interpretation of national policy appears to have been excessively stringent in Liverpool. So the DHSS might be expected to have taken a direct interest in implementing its own policies: for example, it might have tried to devise a national strategy for persuading trade unions to accept change. But of this there is no sign.

Perhaps the most worrying aspect of the Liverpool inquiry is that it should have been necessary in the first place. The committee of inquiry has done an excellent job, particularly considering that it delivered its report within four months of meeting for the first time. But it must surely have been apparent before last summer's explosion that relations within the NHS were turning sour in Liverpool. Why was not Mersey RHA monitoring Liverpool AHA to make sure that it was introducing an effective system for handling industrial relations? And why was not the DHSS monitoring Mersey RHA to ensure that it was keeping an eye on Liverpool ? Did the Secretary of State know what was going on ? If he did not, then there must be some very serious doubts about the effectiveness of the whole NHS managerial structure. If he did know, but did not do anything about it, then there must be serious doubts about the effectiveness of $\mathrm{Mr}$ David Ennals.

The reactions of the Secretary of State to the Liverpool report will therefore be almost as significant as the report itself. This has exposed some central weaknesses in the NHS, and demands answers to two questions. Firstly, given the central importance of industrial relations in the NHS, is the present structure equipped to cope? Secondly, who is accountable when things go wrong-and, more specifically, should members of health authorities who fail to deliver the goods (some of whom appear to take little interest in their responsibilities) remain in office? If accountability means anything, then surely it implies that someone, somewhere, must carry the can for mistakes. Or doesn't the buck stop anywhere in the NHS?

${ }^{1}$ Mersey Regional Health Authority, Report of a Committee of Inguiry, January 1978.

${ }^{2}$ Logan, R F L, et al, Dynamics of Medical Care. London, London School of Hygiene and Tropical Medicine, 1972.

${ }^{3}$ House of Commons, Ninth Report from the Committee of Public Accounts, Session 1976-7.

4 Department of Health and Social Security, Sharing Resources for Health in England, Report of the Resource Allocation Working Party. London, HMSO, 1976.

\section{Birth trauma in vaginal breech delivery}

The more obvious severe injuries associated with vaginal breech delivery are likely to kill the child. They include intracranial $\mathbb{Q}$ haemorrhage associated with tentorial tears, rupture of the $\leftarrow$ liver or spleen, and fracture dislocation of the cervical spine. $\overrightarrow{\vec{F}}$ Other injuries may be less obvious and their implications for future health have yet to be established.

For example, it is surprising that arterial occlusion has only $\frac{\bar{F}}{\vec{D}}$ recently been recognised as a cause of brain damage in new- $\stackrel{\mathbb{Q}}{\varrho}$ born infants. Yates ${ }^{12}$ examined the necks of 60 infants who died during or shortly after birth. Looking especially for $\vec{\circ}$ histological evidence of trauma, he found haemorrhage into the adventitial coat of one or both vertebral arteries in 24 cases. $\vec{\omega}$ These haematomas were often of considerable size, narrowing $\frac{}{0}$ the lumen of the vessel, and in one case the left vertebral artery? was completely occluded. Yates ${ }^{1}$ argued that these vascular $\vec{\cdot}$ injuries (which may be missed if the necropsy technique is not painstaking) could, if the child survived, be the cause of neurological disabilities in later life, but this has still to be $\frac{\omega}{0}$ substantiated.

The manipulation of trunk and limbs in breech delivery may cause muscle damage, sometimes severe and associated with $\vec{\longrightarrow}$ intramuscular coagulation, and there may also be evidence of $\mathbb{P}$ the crush syndrome in other organs. ${ }^{3}$ The frequency of this particular complication of breech birth is probably underestimated, for its recognition depends on extensive dissection $\overrightarrow{0}$ of the muscles-possible only if the child dies and even then only if the necropsy is sufficiently detailed. In a male fetus prolapse of the scrotum through a partially dilated cervix may result in severe congestion and even necrosis of the scrotal skin. The long-term effects of this injury on the growth of the testes is unknown ${ }^{4}$; however, the steady reduction in the past $\stackrel{\otimes}{\mathbb{Q}}$ decade in the length of labour has probably reduced the $\vec{\overrightarrow{ }}$ frequency of scrotal damage.

In contrast, the continued importance of injury to the occipital bone during delivery of the aftercoming head has been emphasised by Wigglesworth and Husemeyer. ${ }^{5}$ In the period 1966-76 in the Hammersmith Hospital death was associated with intracranial trauma in 17 breech-born infants; in $\frac{\sigma}{3}$ five of the 17 cases the traumatic injury was separation of the $\frac{3}{6}$. squamous and lateral parts of the occipital bone (occipital $\delta$ osteodiastasis) with haemorrhage into the posterior cranial fossa. This lesion is likely to be missed unless the postmortem examination includes dissection of the suboccipital region o before opening the skull. A preliminary lateral skull radio- $D$ graph may help to show it up. But for the careful necropsies on these infants their deaths would probably have been attri- $N$ buted to the accompanying tentorial tears rather than to the occipital bone injury and the associated disruption of underlying vascular channels. Like Hemsath, ${ }^{6}$ Wigglesworth and Husemeyer believe the injury is produced, in most cases, $\stackrel{\mathbb{D}}{\mathscr{D}}$ by impingement of the suboccipital bone against the mother's $?$ symphysis pubis, though one of their five cases was thought to be due to forcible engagement of the fetal head in the brim $\stackrel{\mathbb{D}}{\stackrel{D}{*}}$ of the maternal pelvis. Presumably in less severe degrees of $\frac{\mathbb{Q}}{\mathbb{Q}}$ occipital osteodiastasis the child survives, and the Hammersmith report suggests that ataxic cerebral palsy (as found by Neligan $^{7}$ in two out of 185 infants born breech first and examined five years later) is the neurological disorder one would expect to find in survivors.

This important form of birth trauma may occur more frequently than is generally recognised; yet with care it ought 